\title{
On a nonlinear fractional order model of novel coronavirus (nCoV-2019) under AB-fractional derivative
}

\author{
Azhar Hussain ${ }^{1}$ and Saman Yaqoob ${ }^{1}$ \\ ${ }^{1}$ University of Sargodha
}

April 28, 2020

\begin{abstract}
Utilizing the model of novel coronavirus given by Chen $\{\backslash$ it et al. $\}$ [A mathematical model for simulating the phase-based transmissibility of a novel coronavirus, Infectious Diseases of Poverty, (2020) 9:24], we intend to generalize the model to fractional order derivative in Atangana-Baleanu sense and to show the existence of solution for the fractional model using Schaefer's fixed point theorem and for the uniqueness of solution we make use of Banach fixed point theorem. By using Shehu transform and Picard successive iterative procedure, we explore the iterative solutions and its stability for the considered fractional model.
\end{abstract}

\section{Hosted file}

Manuscript_Chen Model.pdf available at https://authorea.com/users/312836/articles/443400-ona-nonlinear-fractional-order-model-of-novel-coronavirus-ncov-2019-under-ab-fractional-derivative 